\title{
Research Paper: Effective Factors Contributing to Acceptance of People With Disability in the Society (Case Study: Shahrekord)
}

\author{
Shahrbanoo Ghafarpoor Nafchi ${ }^{1},{ }^{*}$ Asghar Mohammadi ${ }^{1}$
}

1. Department of Sociology, Dehaghan Branch, Islamic Azad University, Isfahan, Iran.

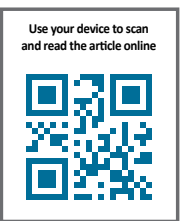

Cftation: Ghafarpoor Nafchi Sh, Mohammadi A. [Effective Factors Contributing to Acceptance of People With Disability in the Society (Case Study: Shahrekord) (Persian)]. Archives of Rehabilitation. 2017; 18(3):202-211. http://dx.doi.org/10.21859/ jrehab-1803202

http://dx.doi.org/10.21859/jrehab-1803202

Received: 31 Mar. 2017 Accepted: 21 Aug. 2017

Keywords:

Disability, Type of disability, Acceptance, Rehabilitation, Training

\section{ABSTRACT}

Objective The present study tries to examine the effective factors contributing to the acceptance of people with disability in the society.

Materials \& Methods The study included 4058 disabled persons supported by Welfare Organization of Shahrekord ( 2474 motional-physical, 673 eyesight, and 911 hearing disability). According to quota sampling method, the statistical sample was 352, which consisted of 58 blind, 80 deaf and 214 motionalphysical people with disability. A researcher-made questionnaire was used for gathering the data. Face validity method and Cronbach's alpha test were used for determining the validity and reliability of the questionnaire. The questionnaire was affirmed by advisor and experienced professor and by using Cronbach's alpha method for variables of social acceptance of people with disability, social capital, family support, manner of spending leisure, presenting rehabilitation services, transportation facilities, mass media programs, personality characteristics and training, which were found to be $82 \%, 86 \%, 94 \%, 82 \%$, $93 \%, 85 \%, 79 \%, 92 \%$ and $87 \%$, respectively.

Results Results of Pearson correlation coefficient showed that there was a significant relationship among variables such as social capital, transportation facilities, manner of spending the leisure, presenting rehabilitation services, training and entrepreneur, social media programs, personality characteristics, family support and acceptance of people with disability $(P<0.001)$. There was no relationship between variables such as type $(P=0.108)$, history $(P=0.531)$ and reason of disability $(P=0.427)$ and acceptance of people with disability in the society. According to the results of variance analysis and t-test in terms of demographic characteristics of people with disability, there was no significant difference between gender $(P=0.071)$ and age $(P=0.498)$ and acceptance of people with disability. But, there was a significant difference between education level, occupation of people with disability, and their societal acceptance $(P<0.001)$. People with disability who were highly educated had a higher acceptance in the society. Also, there was a significant difference between marital status $(P=0.032)$ and education level of spouse $(P=0.046)$ and acceptance of people with disability.

The most important effective factors on acceptance of people with a disability include social capital $(B=0.240)$, family $(B=0.198)$, type of disability $(B=0.164)$, social media programs $(B=0.163)$, transportation facilities $(B=0.159)$, and entrepreneur and training $(B=0.129)$.

Conclusion Acceptance of people with disability is necessary for their presence in the society and their social relations. We should provide the opportunity for their presence in the society and improve their life through creating proper conditions and possibilities.

\section{* Corresponding Author:}

Asghar Mohammadi, PhD

Address: Department of Sociology, Dehaghan Branch, Islamic Azad University, Isfahan, Iran.

Tel: +98 (913) 4085119

E-Mail: asmohamadi@dehaghan.ac.ir 


\title{
عوامل مؤثر بر يذيرش افراد داراى ناتوانى در جامعه (مطالعه موردى: شهركرد)
}

\author{
شهربانو غفاريور نافجى'، "اصغر محمدى'
}

1-5روه جامعهشناسى، واحد دهاقان، دانشُّاه آزاد اسلامى، اصفهان، ايران.

\begin{abstract}
حكبe

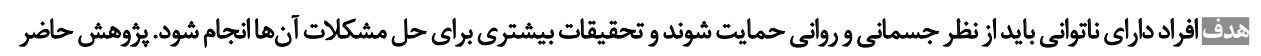

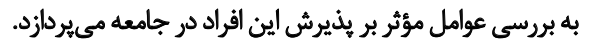

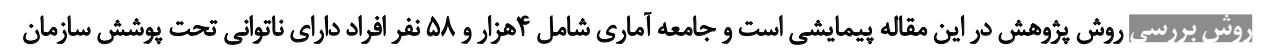

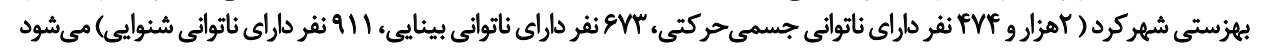

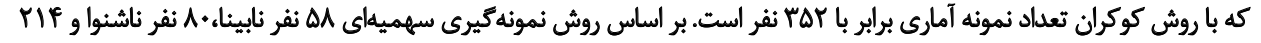

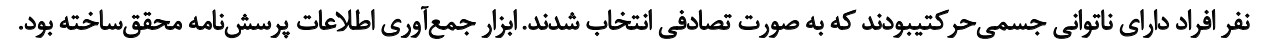

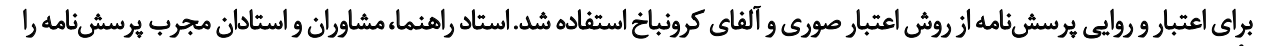

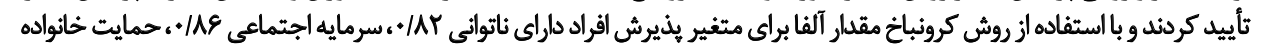

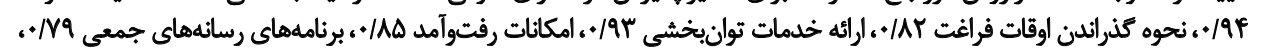

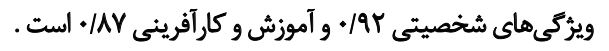

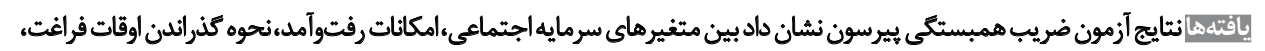

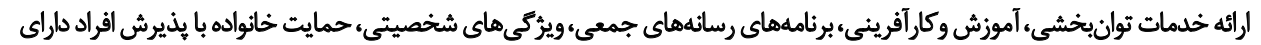

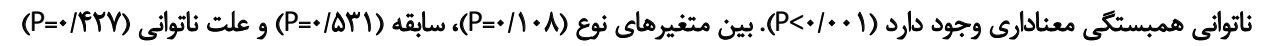

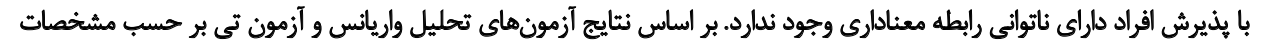

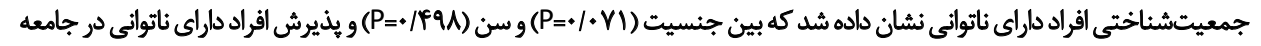

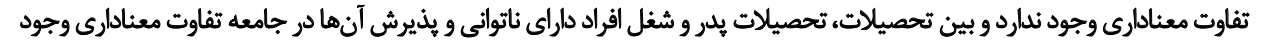

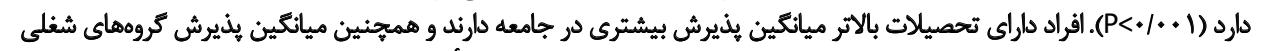

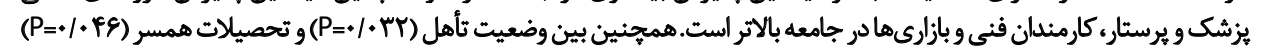

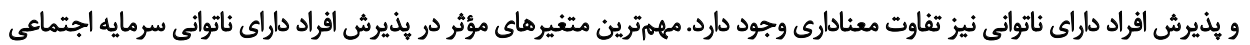

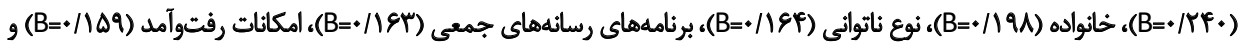

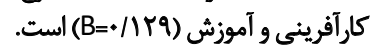

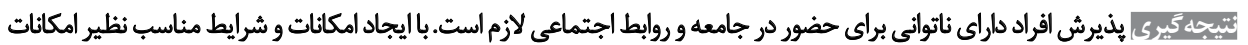

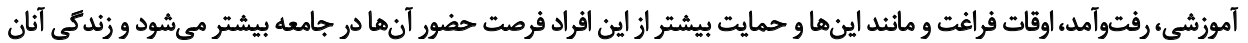

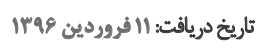

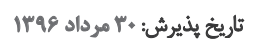

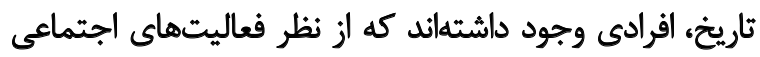

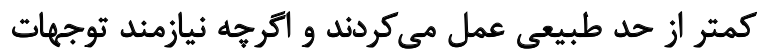
ويرٔاى بودهاند، نهتنها به خواستههاو امور اجتماعى و ورئد رفاهى آنان

ناتوانى' اصطلاحى نسبى و مانعى در برابر انسان براى انجام

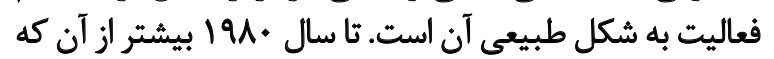

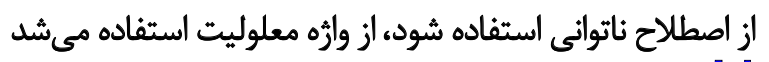

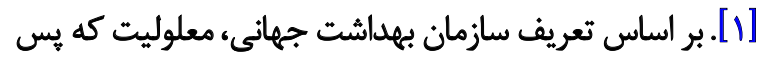
1. Disability

\section{-}


جسمانى اين افراد نبايد آنها را از حقوق فرهنكي و اجتماعى

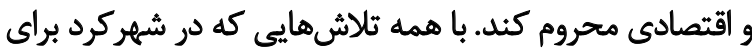

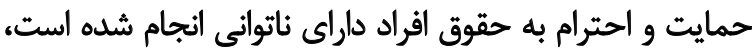

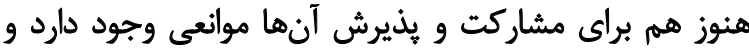
احتمال دارد ناديده كرفته شوند.

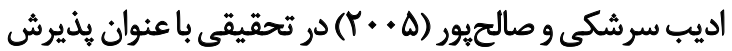

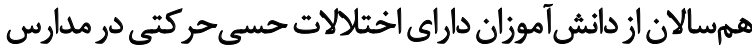

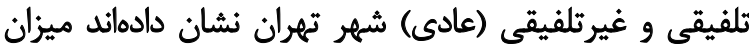

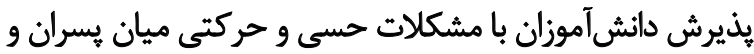

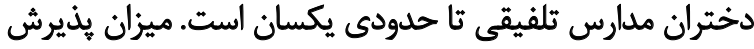

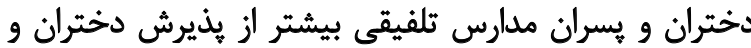

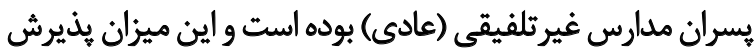

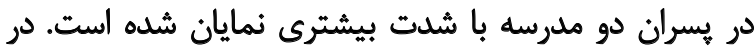

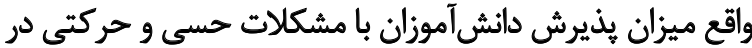

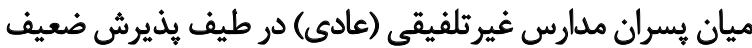

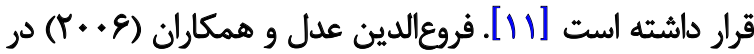

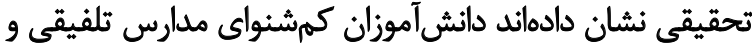

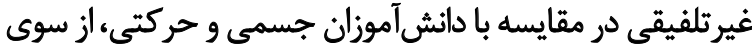

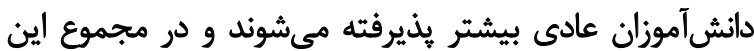

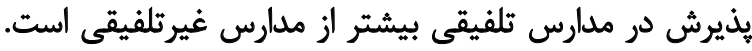

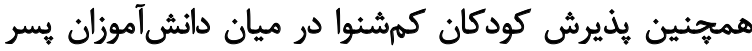

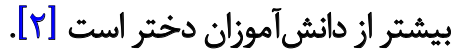

تقوى لاريجانى و همكاران (9 • • (T) در نتايج تحقيق خود عنوان

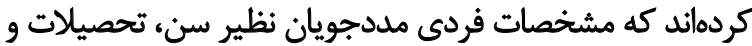

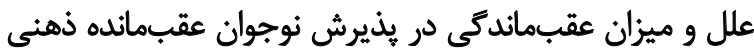

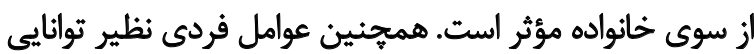

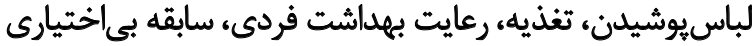

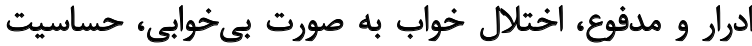

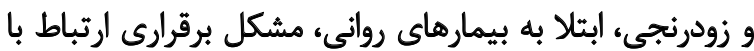

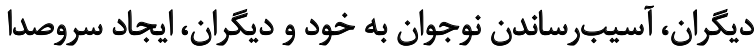

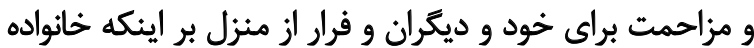

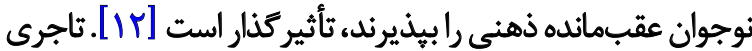

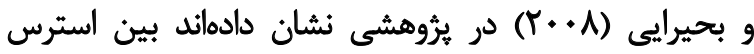

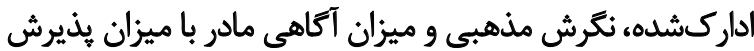

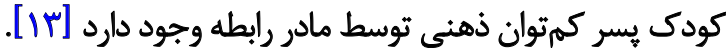

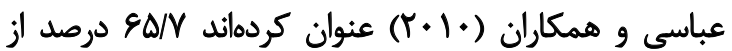

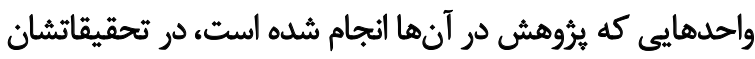

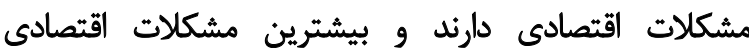

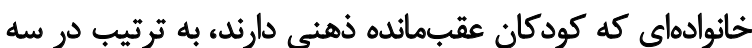

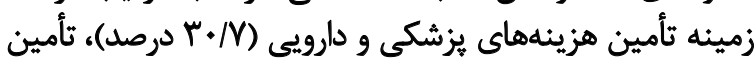

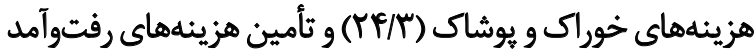
جماع (YM/Q)

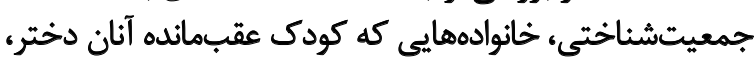

تا قبل از قرن نوزدهم توجه جيندانى نمي شيد، بلكه تاريخ نشان

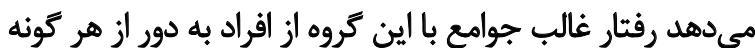

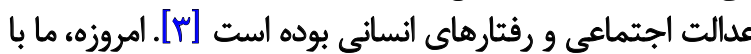

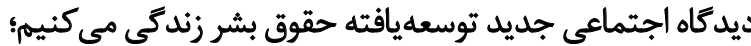

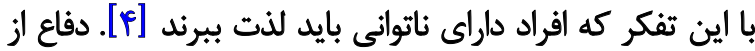

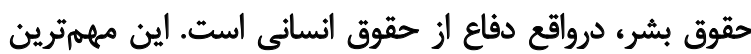

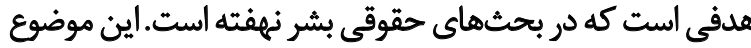

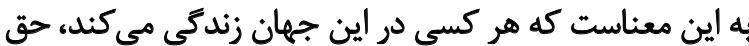

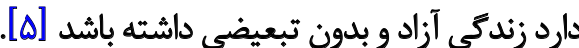

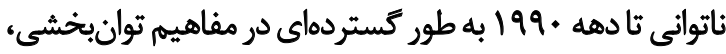

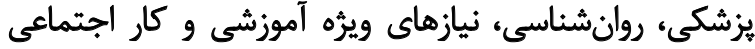

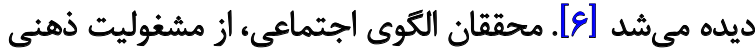

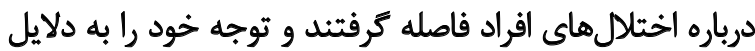

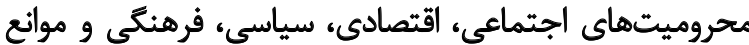

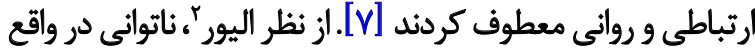

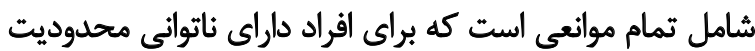

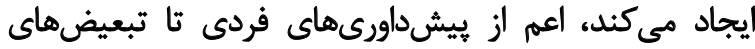

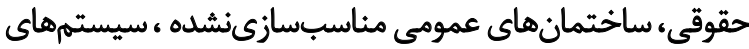

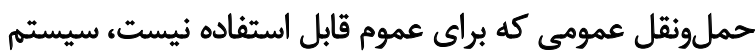

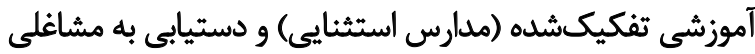
كه در انحصار افراد غيرناتوان است [A]].

حضور بيش از يك ميليارد فرد داراي ناتوانى در جهان كه

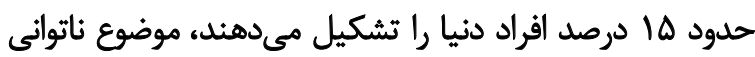

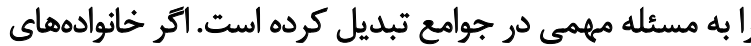

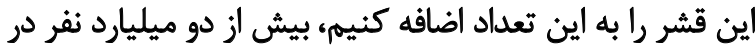

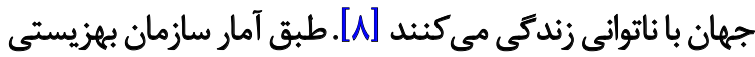

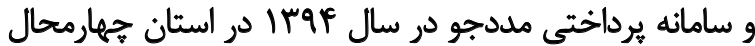

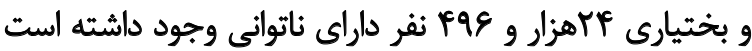
كه از اين تعداد، مهزار و اعV أنفر در مركز استان يعنى شهركرد

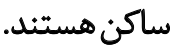

افراد داراى ناتوانى با جالشهاى زيادى در خانواده و جامعه

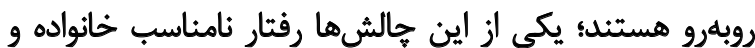

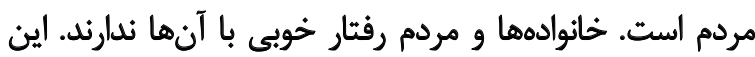

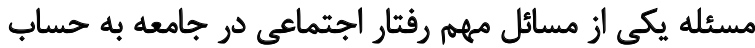

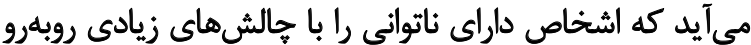

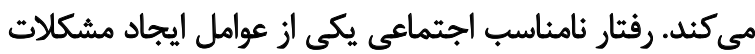

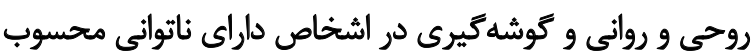

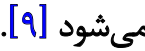

با بيدايش ضايعه و بروز نشانههاى ضعف جسمانى، اتكاى افراد

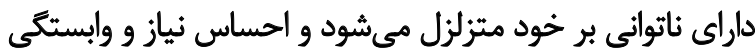

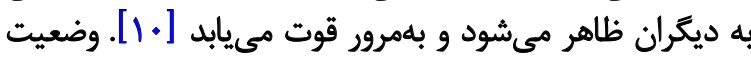

\section{Oliver}




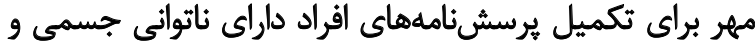

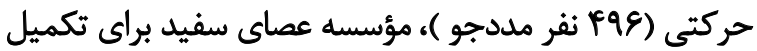

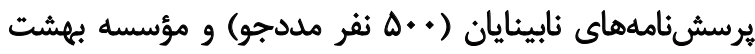

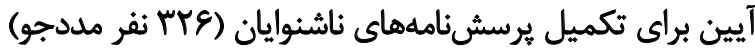

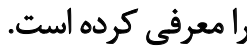

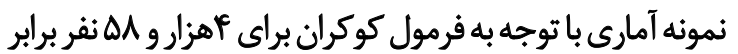

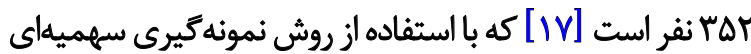

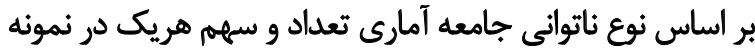

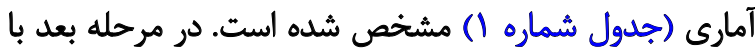

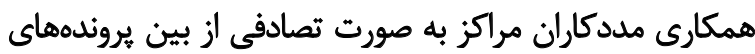

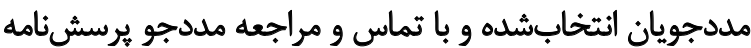

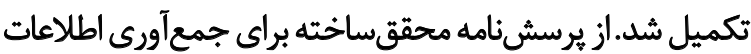

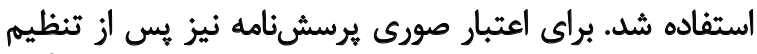

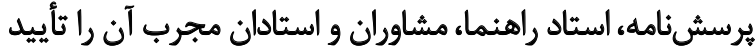

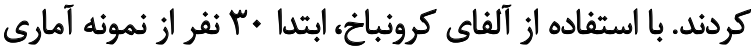

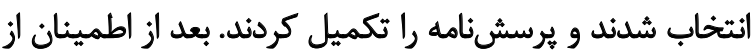

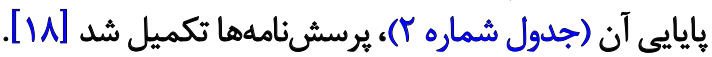

يافتهها

دادههاي بلدستآمده از جدول شماره ب نشان مي دهد بين

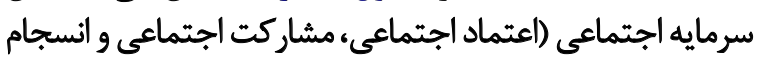

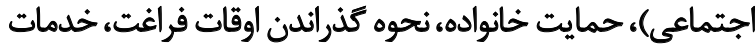

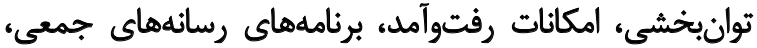

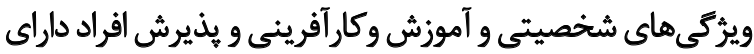

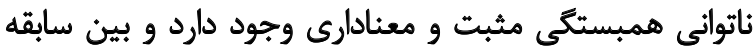

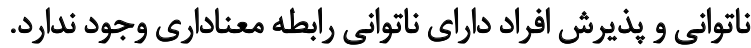

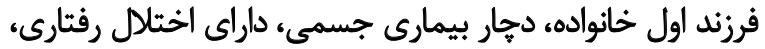

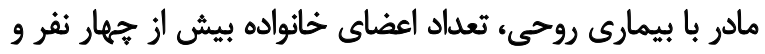

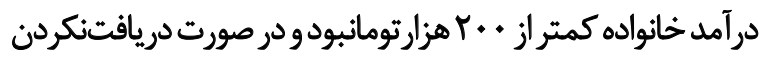

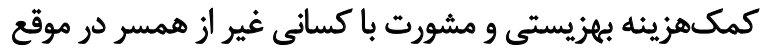

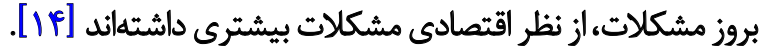

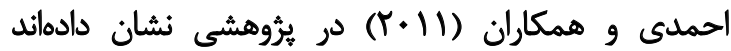

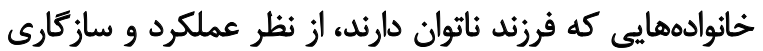

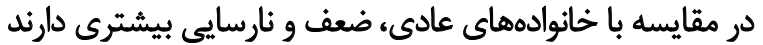

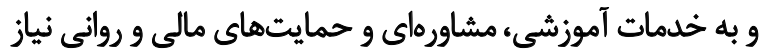

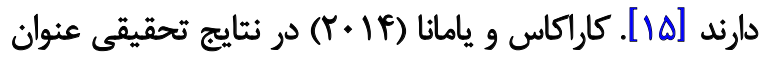

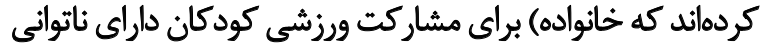

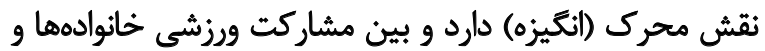

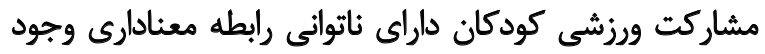

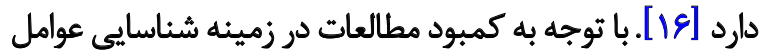

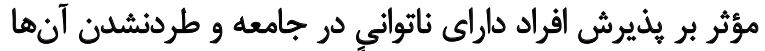

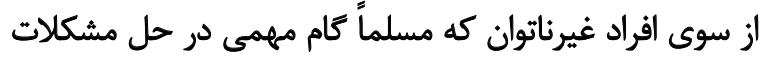

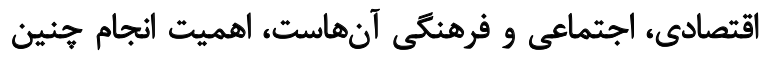

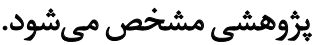

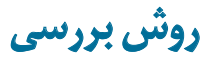

درش تحقيق در اين يُروهش بيمايشى بود. يُروهش حاضر

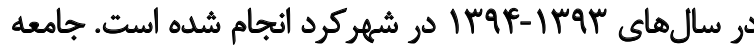

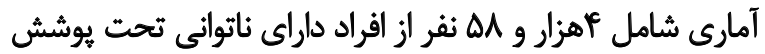

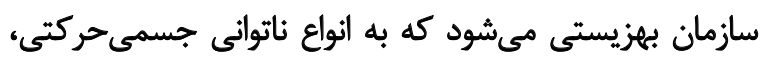

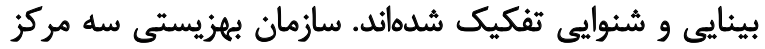
تحت نظارت سازمان بهزيستى شامل مؤسسه خيريك شيريه آيين

جدول ا. تعداد نمونه آمارى به تفكيك نوع معلوليت

\begin{tabular}{|c|c|c|c|}
\hline تعداد (نموثه أمارى) & درصد & تعداد (جامعه آمارى) & نوع معلوليت \\
\hline MIF & 9.19 & ment & جسمى كتى \\
\hline $\mathrm{AM}$ & $18 / 8$ & $e n$ & بيينايى \\
\hline ᄉ. & $r M / F$ & 911 & شنوايى \\
\hline rat & $1 .$. & $Y+Q A$ & جمع \\
\hline
\end{tabular}

جدول Y. مقدار آلفا

\begin{tabular}{|c|c|c|c|c|c|c|c|c|c|}
\hline كارأفرينى & شُخْئى هايتى & رسمعى رئى & رفتوآمد & تواندخشمى حُبث & فراغتث & خانواديت & سترمايه & ثذارير شاتي افراد & ألثا \\
\hline$\Lambda$ & 1. & $r$ & 8 & 9 & f & $\checkmark$ & ir & if & تعلاد سؤالات \\
\hline.$/ 19$ & .119 & $\cdot M$ & ./AF &.$/ M$ & - IAT &.$/ 9 \Delta$ & $\cdot / A_{0}$ & $\cdot|A|$ & •"كفر \\
\hline$\cdot / A Y$ &.$/ 9 r$ & .199 & $+/ \Delta \Delta$ & ש9/. & . AAr & $+/ 9 F$ & 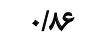 & + /AT & ror نفر \\
\hline
\end{tabular}


جدول "ا. نتايج آزمون ضريب همبستيكى ييرسون

\begin{tabular}{|c|c|c|c|c|c|c|}
\hline امكانات رفتوأمد & توانبخشيى & نحوه كذراندن اوقات & حمايت خانواده & سرمايه اجتماعى & سابقه ناتوانى & مثغير \\
\hline.$/ T Y A$ &.$/ 709$ &.$/ F a q$ &.$/ F a$ &.$|\Delta|$ & $-.1 \cdot \pi$ & ضريب همبستكى \\
\hline$\%$ & $\%$ & $1 \ldots$ & $+\ldots$ & $+1+*$ & / /هrI & سطح معناداري \\
\hline انسجام اجتماعى & مشاركت اجتماعى & اعتماد اجتماعى & كارأفرينى & شيخرَى هايتى & رسائه هاى جمعى & مثغير \\
\hline.$/ F q$ &.$/ T W$ & $+/ t+8$ & +/Fap & $+/ F n$ & $+/ f+r$ & ضريب همبستكى \\
\hline 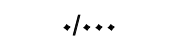 & 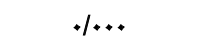 & $\%$ & 10. & $\%$ & $\%$ & سطح معنادارى \\
\hline
\end{tabular}

توانبخننى

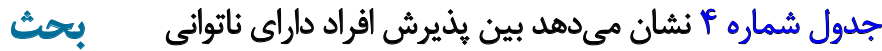

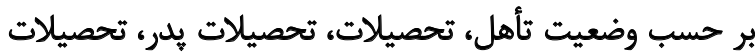

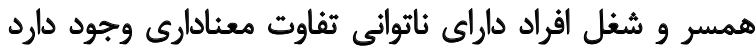

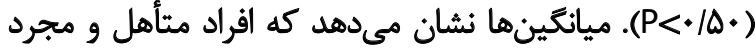

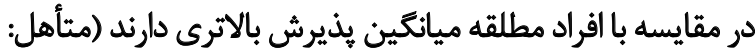
TI/TF

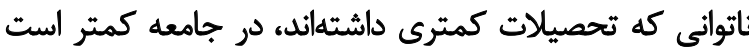

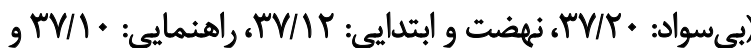

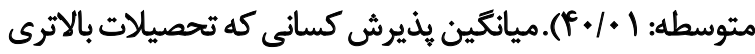

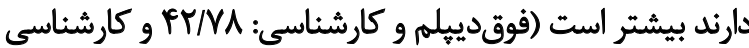

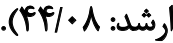

اوقات فراغت به عنوان بديدهاي فرهنكىاجتماعى كه در ابعاد

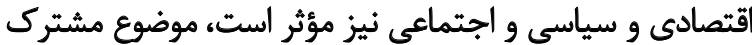

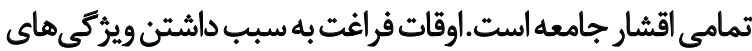
خاص، هم طرف توجه دستاندركاران تعليم و تربيت و مسئولان ونان

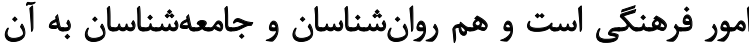

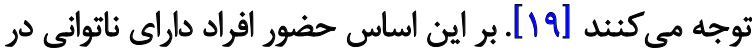

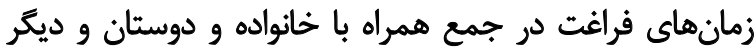

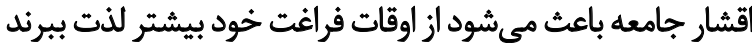

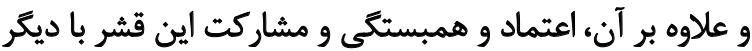

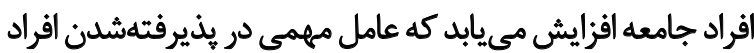
داراى ناتوانى است.

به نظر كلمن،سرمايهاجتماعى تركيبى از ساختارهاى اجتماعى دئى

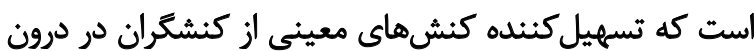

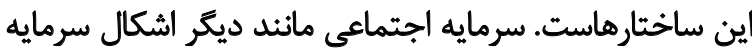

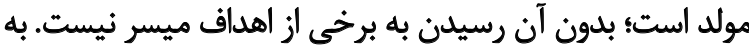

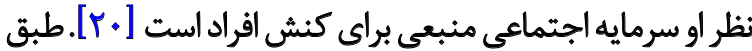

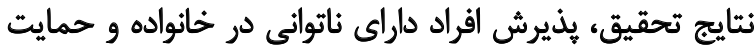

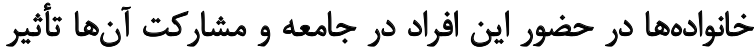

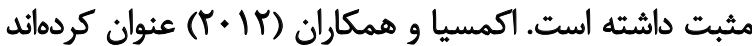

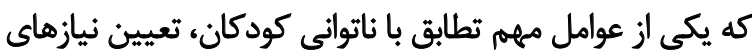

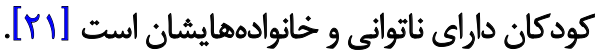
افراد ناتوانى كه بدرشان بى بـوادواد است، كمترين ميانكين

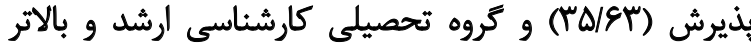

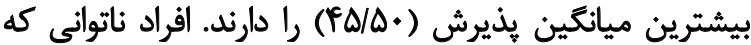

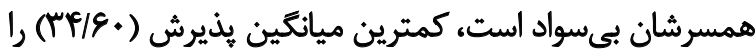

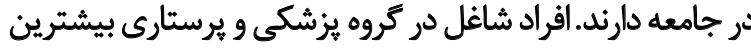

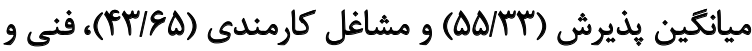

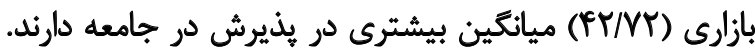

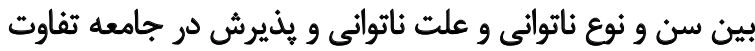

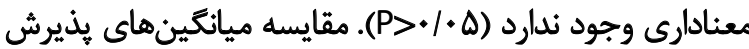

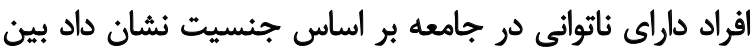

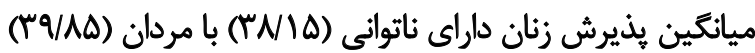

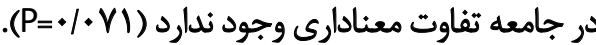

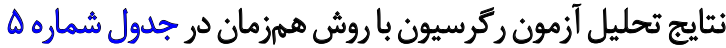

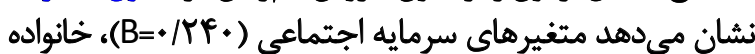

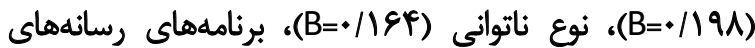

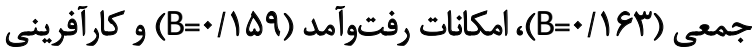

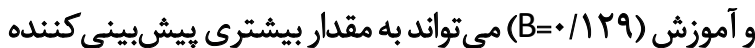

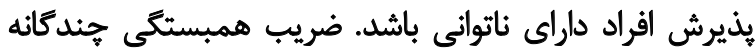

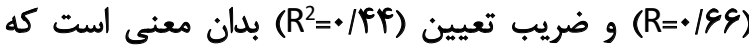

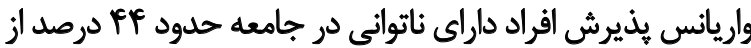

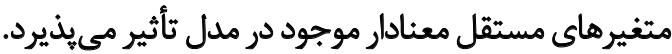




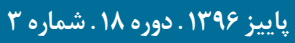

توانفخنقى

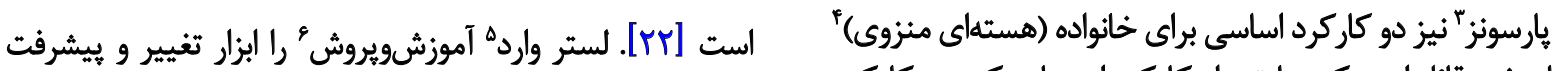

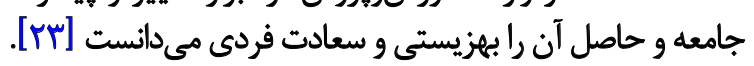

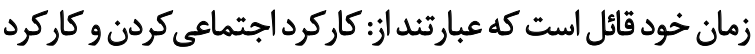

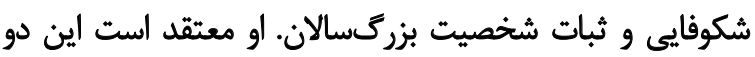

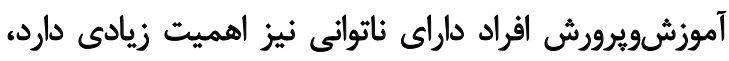

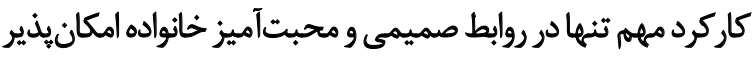

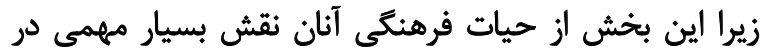

جدول ع. نتايج آزمون تحليل واريانس يذيرش افراد داراى ناتوانى برحسب نوع و علت ناتوانى، وضعيت تأهل، سن، تحصيلات، تحصيلات يدر، تحصيلات همسر و شغل

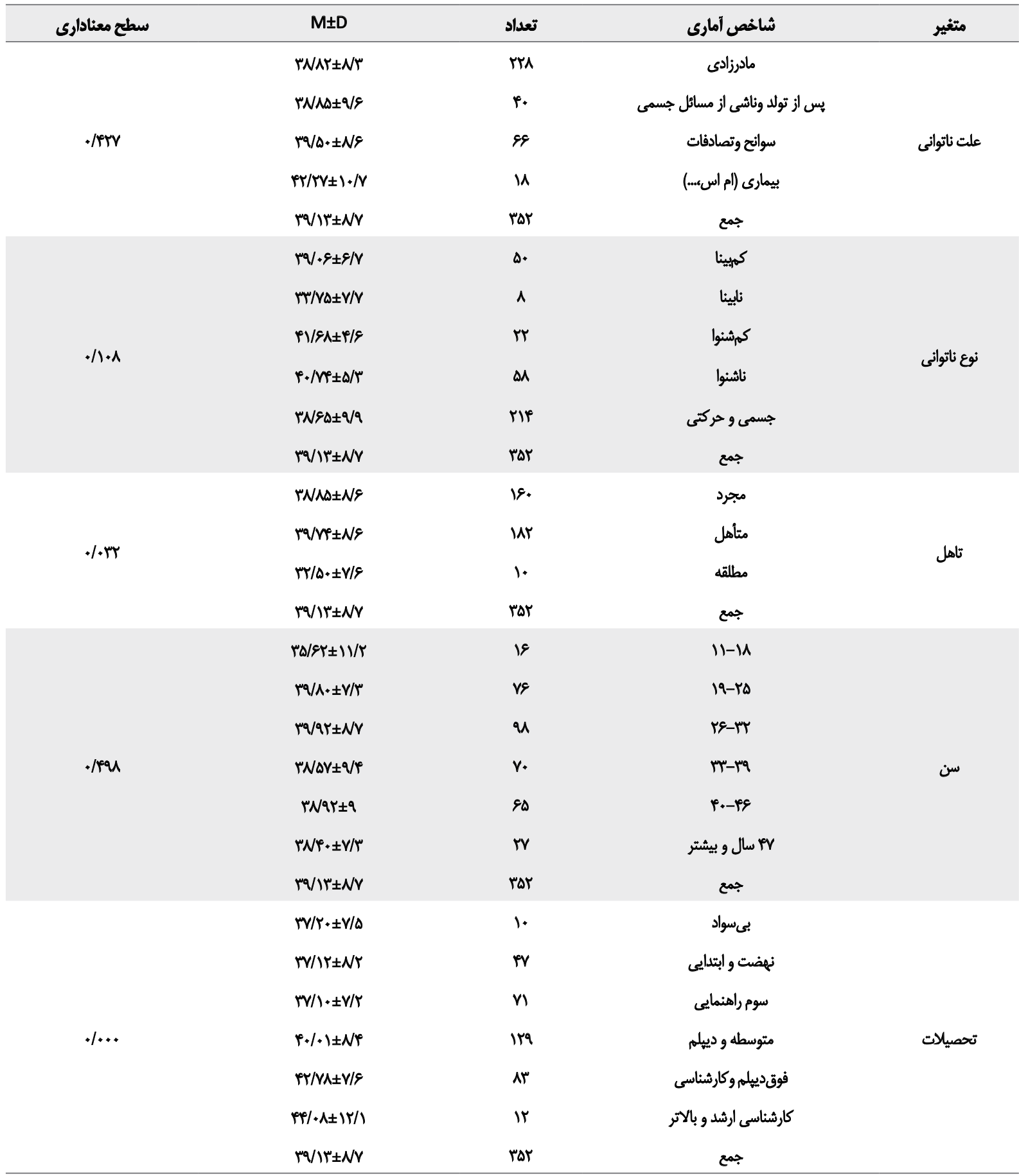

5. Lester Ward

6. Education and Training
3. Parsons

4. Nuclear family

$r+V$

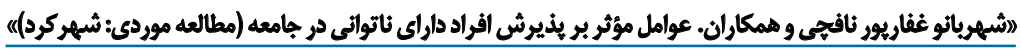




\begin{tabular}{|c|c|c|c|c|}
\hline سطح معنادارى & $M \pm D$ & تعداد & شاخص آمارى & متغير \\
\hline \multirow{8}{*}{$\%$} & $r \Delta / q T \pm q / 1$ & $1 . Y$ & بي نسواد & \multirow{8}{*}{ تحصيلات يلر } \\
\hline & $P \cdot M+ \pm N \mid$ & $1+1$ & نهضت و ابتدايي & \\
\hline & $r+/ 8 T \pm V / Q$ & va & سوم راهنمايى & \\
\hline & $P T / K \cdot \pm N R$ & r. & متوسطله ودييلم & \\
\hline & $P I / T Q \pm N T$ & r & فوقدييلمه وكارششاسى & \\
\hline & $P \Delta / \Delta \cdot \pm 1 r / 1$ & r & كارشناسى ارشد و بالاتر & \\
\hline & $f= \pm V /$ & $\Delta$ & فُوتشده & \\
\hline & PQVIT $\pm N V$ & rat & جمع & \\
\hline \multirow{7}{*}{.1 .48} & $m / \varepsilon \cdot \pm \Delta / \varepsilon$ & 1. & بيىسواد & \multirow{7}{*}{ تحصيلات همسر } \\
\hline & $r V / F i \pm 1 \cdot N$ & re & نهضت و ابتدايى & \\
\hline & एจ/१| \pm Y/\& & rv & سوم راهنمائي & \\
\hline & $F / \Delta \& \pm E / q$ & er & متوسطه ودييلم & \\
\hline & $F I \pm N q$ & r. & فوقدييله وكارششاسى & \\
\hline & $P Y / \Delta Y \pm I T$ & $v$ & كارششناسى ارشد و بالاتر & \\
\hline & $r q M I \pm N Y$ & Wr & جمع & \\
\hline \multirow{10}{*}{ 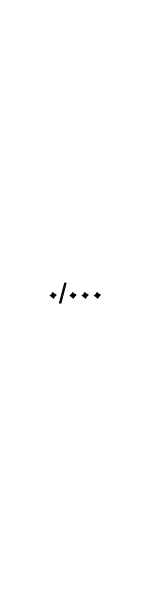 } & $P N \mid \pm E / E$ & $r$ & مديريتى و مهثلدسى & \multirow{10}{*}{ تشغل } \\
\hline & $\Delta \Delta / \pi T \pm Y / \Lambda$ & $r$ & يزشكى و يرستارى & \\
\hline & $r N \&+ \pm \& / N$ & 1. & فرهنكي، علمى و هنرى & \\
\hline & $\pi / / 8 \Delta \pm 1 . / 1 \mathrm{~V}$ & re & كارمند & \\
\hline & $F T M \pm V / V$ & to & فنى و بازارى & \\
\hline & $\nabla V / \Delta \cdot \pm 8 / \Delta$ & $\wedge$ & خحلدمانَى و دفقترى & \\
\hline & $r V \pm g / r$ & if & ساده و دستخفروشى & \\
\hline & $r g / R T \pm 1$ & III & ساير مشاغل & \\
\hline & PQRTYNY & $1 m 9$ & غيرشاغل & \\
\hline & PQITINV & rat & جمع & \\
\hline
\end{tabular}

انسجام بيشترى داشتهاند، خانوادههايشان آنها را يذيرفتهاند و طرد

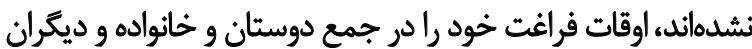

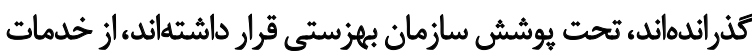

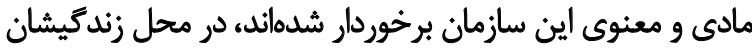

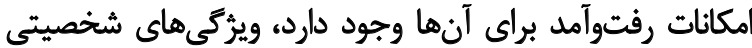

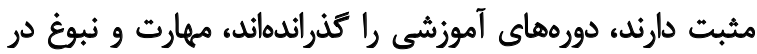

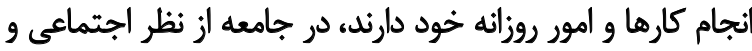

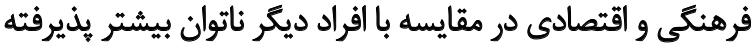
شدهاند و مشاركت و حضورشان در جامعله بيشتر است.

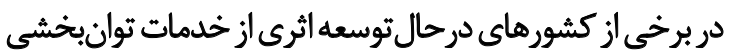

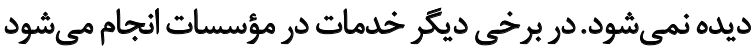
و فقط درصد كمى از نيازمندان از آن استفاده ميكى دنيند. در اين
توانمندشدن، اشتغال و كشف استعداد و توانايى هاى آنان دارد.

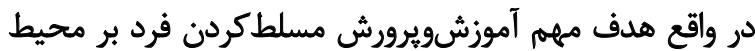

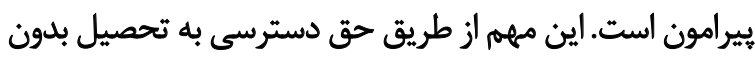

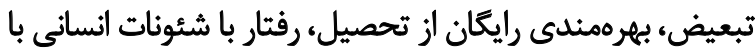

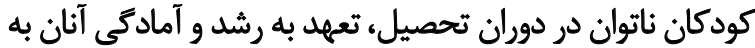

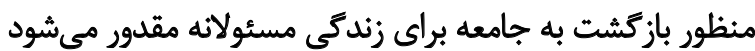

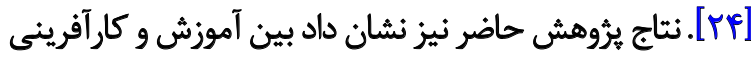

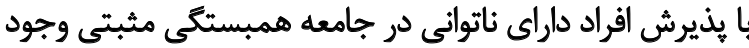

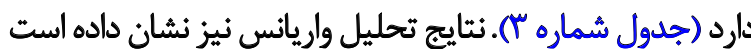

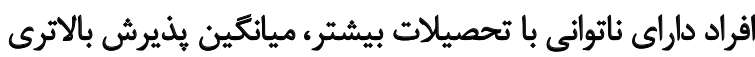

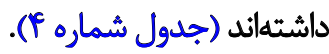
افراد داراى ناتواتيى كه اعتماد اجتماعى، مشاركت و احساس 
جدول ه. ارتباط بين يذيرش افراد داراى ناتوانى با متغيرهاى مستقل

\begin{tabular}{|c|c|c|c|c|c|c|c|c|c|}
\hline $\mathbf{P}$ & df & مجذور R تنظيم شده & $\mathbf{R}^{r}$ & $\mathbf{R}$ & $\mathbf{F}$ & $\mathbf{P}$ & مقدارt & ضريب بتا & شاخصص آمارى \\
\hline & & & & & & $.1 * 1$ & $r / \Delta)$ & .119 & نوع ناثواتى \\
\hline & & & & & & ( & $t / 1 \Delta \omega$ & $D /+H$ & سابقه ناتوانى \\
\hline & & & & & & $+/ \Delta+r$ & $-+18 \mathrm{~V}$ & $-+1 .+4$ & علث ثاتوانى \\
\hline & & & & & & $+\cdots$ & $r / q$. &.$/ \pi$ & سرمايه اجتماعى \\
\hline & & & & & & $\%$ & $\Gamma / \Delta \Delta$ & .114 & حمايت خانواده \\
\hline \multirow[t]{6}{*}{$\%$} & M-M. &.$/ P Y$ &.$/ \mu$ & .189 & $M e / 9 \Delta$ & $.8 \|$ & - MTY & $-\infty .+5$ & كذراندن فراعت \\
\hline & & & & & & . FTY &.$/ F A$ &.$\%$ A & خدمات توانيخشيى \\
\hline & & & & & &.$\% 1$ & $r / T F$ &.$/ 109$ & رفتوآمد \\
\hline & & & & & & $.1 . .1$ & $r / F A$ &.$/ 19$ & برنامههاى ربسانهها \\
\hline & & & & & &.$/ 419$ & ./944 & .1 .91 & ويرّكى هاى شخصيثى \\
\hline & & & & & & .1 .79 & $r / 19$ &.$/ 179$ & كارآقرينى و آموزش \\
\hline
\end{tabular}

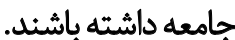

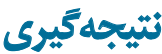

عوامل بسيارى در حضور بيشتر افراد داراى ناتوانى در جامعا فئه

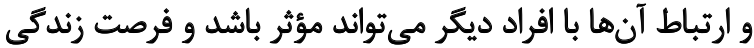

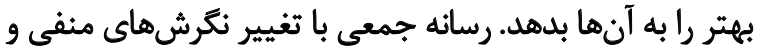

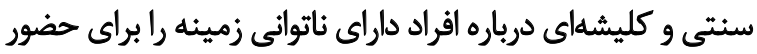

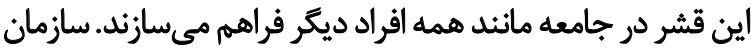

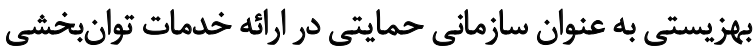

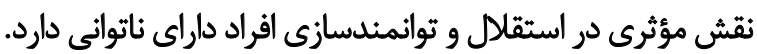

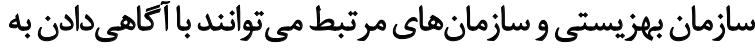

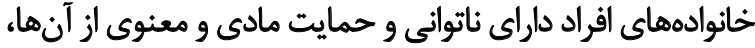

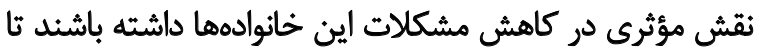

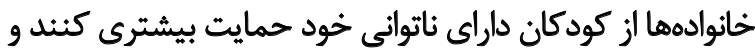
آنها رابيذيرند.

تحصيلات بيشتر باعث مى شود بايكاه اجتماعى و اقتصادى افراد

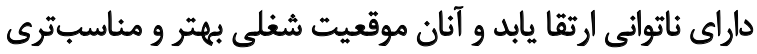

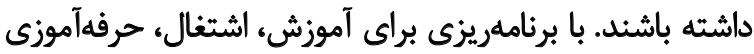

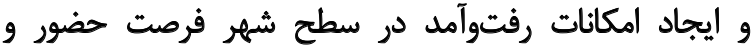

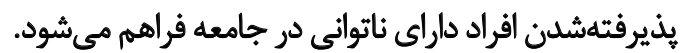
در يايان يادآورى هيند نكته ضرورى به نظر ميروسد. در اين باين

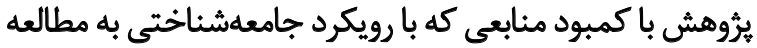

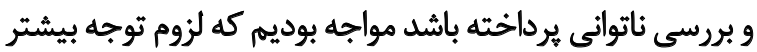

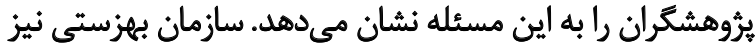

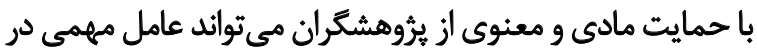

كشورها تنها يك تا سه درصد از جمعيت افراد داراي ناثوانى

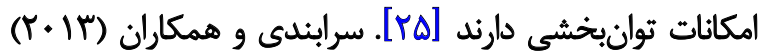

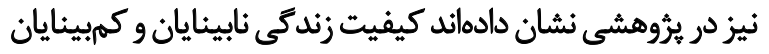
برخوردار از خدمات توانبخشى، بهتر از نابينايان و كمبينايناينان محروم از خدمات است إعبات توانئ.

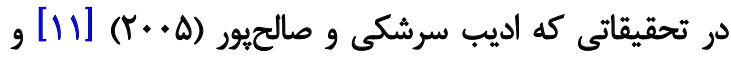

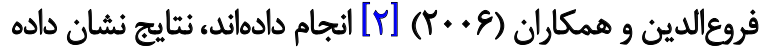

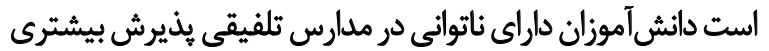

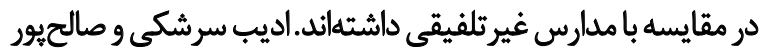

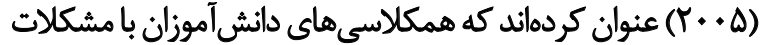

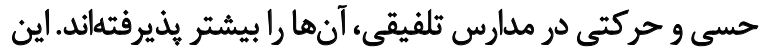

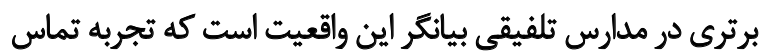

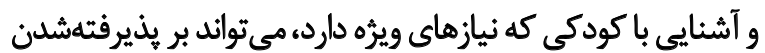
اين كودى از طرف دانش آموزان عادى اثركذار باشد.

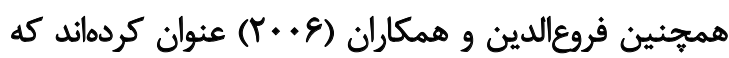

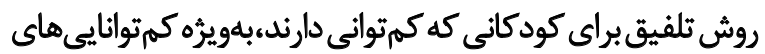

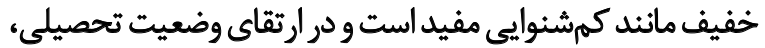

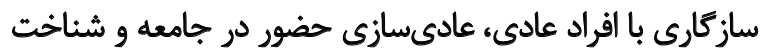

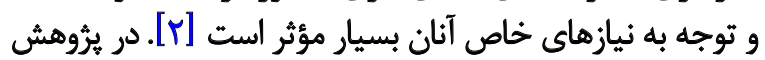

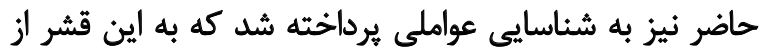

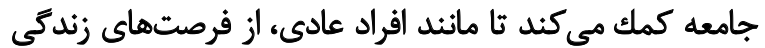

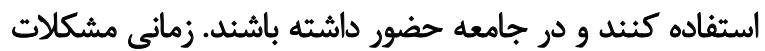

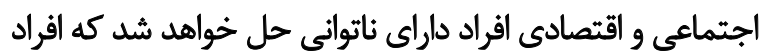

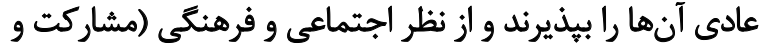

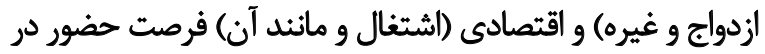


توسعه تحقيق و يُوهش در زمينه مسائل و مشكلات اجتماعى و اقتصادى و فرهنكى اين قشر آسيب يذينير از جامعه باشد.

با توجه به اينكه يكى از عوامل مؤثر بر خيذيرش افراد دارئ

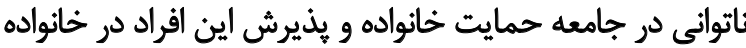

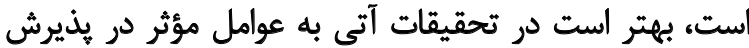

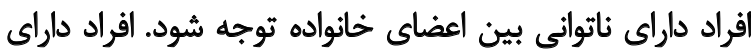

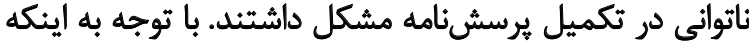

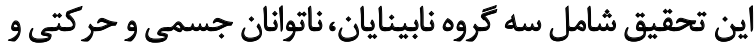

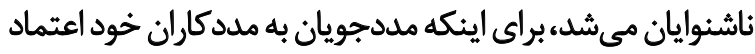

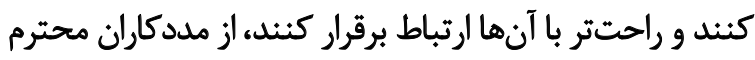

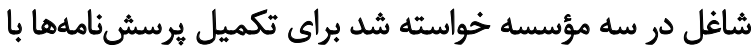

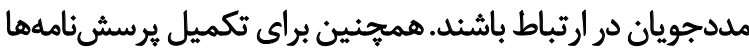

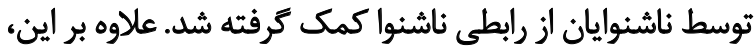

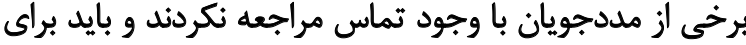

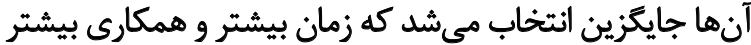

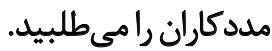

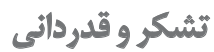

اين مقاله از پايايانامه كارشناسى ارشد خانم شهربانو غُقاريور

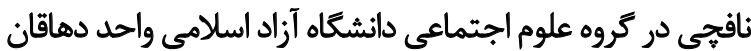

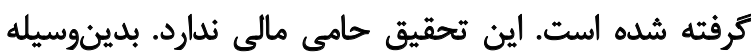

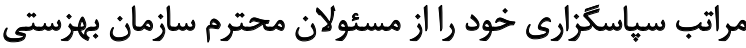

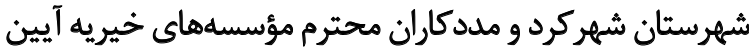

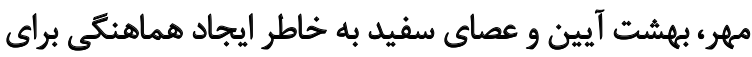

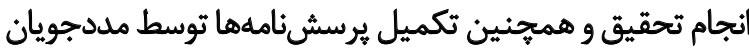

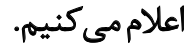




\section{References}

[1] Kamali M, Iran F. [The review on rights of disabled children (Persian)]. Social Welfare Quarterly. 2003; 2(7):93-110.

[2] Foruodinadl A, Biglarian A, Adib-Sereshki N, Sadralsadat S]. [Acceptance of students with physical disability by normal students in inclusive schools of Tehran (Persian)]. Advances in Cognitive Science. 2006; 8(2):66-71.

[3] Majdi F, Teimouri S. [A study of Chaharbagh Avenue as a case study to improve access for war-invalids and physical disabled people (Persian)]. Iran Journal of War \& Public Health. 2011; 3(3):36-44.

[4] Monedero JAG, Cuesta CU, Angulo BN. Social image of disability. Vulnerability of the dignity of women with disability and social exclusion contexts. Procedia-Social and Behavioral Sciences. 2014; 161:115-20. doi: 10.1016/j.sbspro.2014.12.019

[5] .Kamali M. [Disability and human right (Persian)]. Social Welfare Quarterly. 2004; 3(13):41-56.

[6] Hosseini N. [Prevalent patterns of disability studies(Persian)] Peyk-e Tavana. 2014; 6(54):15

[7] Hosseini N. [A look at four patterns in disability studies (Persian)]. Peyk-e Tavana. 2014; 6(54):15.

[8] Soltanifar M, Eftekhar P. [Portrayal of disability in feature films, based on disability models (Persian)]. Journal of Cultural Management. 2013; 7(21):77-94.

[9] Yazdani K. [Islam and disability (Persian)]. $1^{\text {st }}$ edition. kabol: ALSO Institute Publication; 2010.

[10] Ghasmi A, Momeni M, Khankeh HR. [Comparison of body image between disabled athletes, disabled non-athletes and nondisable non-athletes males (Persian)]. Archives of Rehabilitation. 2009; 10(4):26-31.

[11] Adib Sereshki N, Salehpour Y. [The acceptance of students with physical disabilities by their peers in inclusive and non-inclusiveschools in Tehran (Persian)]. Archives of Rehabilitation. 2005; 6(2):29-35.

[12] Taghvai Larijani T, Monjamed Z, Mehran A, Gharahi Ghehi F. Individual factors related to acceptance of mentally retarded adolescent by their family (Persian)]. Hayat. 2006; 12(1):27-34

[13] Tajeri B, Bohayraei AR. [The association of parenting stress, religious attitude, and knowledge with maternal acceptance for sons with mental retardation (Persian)]. Journal of Exceptional Children. 2008; 8(2):205-24

[14] Abbasi S, Fadakar K, khaleghdoost T, SedighiA, Atrkar Roshan Z. [Survey the problems of families with mentally retarded child covered by Guilan Welfare Centers in 2010 (Persian)]. Journal of Holistic Nursing and Midwifery. 2010; 20(63):33-9.

[15] Ahmadi Kh, Khodadadi GhR, Anisi J, Abdolmohammadi E. [Problems of families with disabled children (Persian)]. Journal of Military Medicine. 2011; 13(1):49-52.

[16] Karakas G, Yaman C. The role of family in motivating the children with disabilities to do sport. Procedia-Social and Behavioral Sciences. 2014; 152:426-9. doi: 10.1016/j.sbspro.2014.09.225
[17] Hafeznia MR. [An introduction to research methods in humanities (Persian)]. 16 ${ }^{\text {th }}$ edition. Tehran: SAMT; 2009.

[18] Sarmad Z, Bazargan A, Hejazi E. [Research methodology in behavioral sciences (Persian)]. 14 ${ }^{\text {th }}$ edition. Tehran: Agah; 2007.

[19] Davati A, Jamali A. [Survey of utilization proportion of specific services for leisure time in Tehranian retiredes and related factors (Persian)]. Journal of Social Welfare. 2004; 4(15):123-38.

[20] Azkia M, Ghaffari GhR. [Sociology of development (Persian)]. $9^{\text {th }}$ edition. Tehran: Keihan; 2011.

[21] Akmese PP, Mutlu A, Kayhan N. Perceptions of family needs in mothers of children with physical disabilities. Procedia-Social and Behavioral Sciences. 2012; 46:1122-4. doi: 10.1016/j.sbspro.2012.05.259

[22] .Arazy Sh. [Sociology of family (Persian)]. $8^{\text {th }}$ edition. Tehran: Roshangaran va Farhang-e Zanan; 2012.

[23] Ahanjideh A. [Sociology of organization of education (Persian)]. $3^{\text {rd }}$ edition. Shahrekord: Ahanjideh; 2009.

[24] Tabatabai SA, Noori Neshat S. [Cultural rights of people with disabilities (Persian)]. Qom: Office of Disability Culture; 2011.

[25] Amin-Zadeh A, Hatami-Zadeh N, Mirkhani S M, KazemNezhad A. [Effectiveness of home based training service of Community Based Rehabilitation (CBR) program offered fammilies of physically disabled people (Persian)]. Archives of Rehabilitation. 2004; 5(3):37-44.

[26] Sarabandi A, Mobaraki H, Kamali M, Chabok A, Soltani S. [The effect of rehabilitation Services on quality of life for the blind (Persian)]. Journal of Modern Rehabilitation. 2013; 7(4):48-56. 